Article

\title{
Experimental Study on Acoustic Emission of Confined Compression of Crushed Gangue under Different Loading Rates: Disposal of Gangue Solid Waste
}

\author{
Junmeng $\mathrm{Li}^{1,2}{ }^{1}$, Yanli Huang ${ }^{1,2}, *$, Wen Zhai ${ }^{3}$, Yingshun $\mathrm{Li}^{1,2}$, Shenyang Ouyang ${ }^{1,2} \mathbb{D}$, \\ Huadong Gao ${ }^{1,2}$, Wei $\mathrm{Li}^{1,2}$, Kun $\mathrm{Ma}^{3}$ and Laiwei $\mathrm{Wu}^{1,2}$ \\ 1 State Key Laboratory of Coal Resources and Safe Mining, School of Mines, China University of Mining \& \\ Technology, Xuzhou 221116, China; lijunmeng1201@163.com (J.L.); cumt_liyingshun@163.com (Y.L.); \\ ouyangshenyang@126.com (S.O.); gaohuadong1314@163.com (H.G.); 15094351084@163.com (W.L.); \\ 17865932091@163.com (L.W.) \\ 2 Key Laboratory of Deep Coal Resource Mining of Ministry of Education, China University of Mining \& \\ Technology, Xuzhou 221116, China \\ 3 National Energy Group Ningxia Coal Industry Co. LTD, Yinchuan 750000, China; lvlippa@163.com (W.Z.); \\ xiangyumch@163.com (K.M.) \\ * Correspondence: huangyanli6567@163.com
}

Received: 7 April 2020; Accepted: 8 May 2020; Published: 11 May 2020

\begin{abstract}
The crushed gangue materials which are filled into the goaf in solid-backfilling coal mining become the main body of bearing the overburden after the tamping process. Its resistance to deformation is the key to control overburden movement and surface subsidence. Particle breakage affects the resistance to deformation of filling materials. In this paper, a confined compression test of crushed gangue under different loading rates was designed, and the acoustic emission (AE) signal was monitored in the process of confined compression. The test results showed that with the increase of loading rate, the anti-deformation ability of crushed gangue showed a dynamic change process of increasing, decreasing, and then increasing again. With the increase of loading rate, the breakage degree of the samples decreased, the proportion of large-sized gangue increased, the growth period of AE counts showed an obvious hysteresis phenomenon, and the AE activity level of the gangue increased gradually. The research results can not only provide a more in-depth and comprehensive understanding of the mechanical properties of crushed gangue filling materials but also provide a reference for the engineering application of solid-filling coal mining.
\end{abstract}

Keywords: sustainable development; loading rate; crushed gangue; confined compression; acoustic emission (AE)

\section{Introduction}

Solid-backfilling mining can effectively control strata movement and surface subsidence and improve the "three-below" (under the railway, under the water, under the structure) coal resources recovery rate. It is very important to understand the mechanical properties of compaction of fill [1-6]. Under the action of overlaying pressure, the solid filling body in the goaf will show a loading rate effect, and the mechanical properties of the gangue filling body will change with the change of the loading rate [7-10].

There is considerable research on the loading rate effect of rocks. Xue [4] studied the mining dynamic response and failure mechanism of coal and rock under different loading modes and loading rates based on uniaxial tension and compression, conventional triaxial, and dynamic tests. Cao et al. [11-13] studied the effect of loading rate on uniaxial compressive strength and acoustic 
emission characteristics of cemented tailings backfill. Song et al. [14,15] analyzed the corresponding relationship between the loading rates and local evolution characteristics of rock deformation, the variation of Poisson's ratio, and the characteristics of energy accumulation and release through uniaxial compression tests of red sandstone under different loading rates. Li et al. [16-18] studied the effect of loading rate on the mechanical behavior of the medium through uniaxial mechanical tests of coal at different loading rates. Xie [19] studied the influence of mining rate on the mechanical characteristics of the surrounding rock of a fully mechanized caving face. Cao et al. [20] conducted an experimental study on the damage evolution rule and acoustic emission (AE) parameters characteristics of sandy mudstone under different loading rates and proposed a stress-strain constitutive model based on the rock damage. Jiang et al. [21] studied the influence of loading rate on the energy accumulation and dissipation in rocks with the FLAC3D software and rock CT scanning. Xiao et al. [22,23] carried out acoustic-charge monitoring tests for coal fracture process under different loading rates and established acoustic-emission charge criteria for different instability forms of coal under different loading rates. However, there are few studies on the effect of loading rate on the crushed-gangue fill materials used for backfill.

In order to reveal the mechanism of the effect of loading rate on the crushing characteristics and bearing capacity of the crushed gangue, an $\mathrm{AE}$ test of loose-gangue compaction under different loading rates was designed.

\section{Materials and Methods}

\subsection{Material Characterization}

The sandstone-type "tunneling gangue" was used in this study. It was composed mainly of $37 \%$ quartz, some illite, a mixture of illite and smectite, as well as small amounts of chlorite. As for the chemical composition of the sandstone-type "excavation gangue" samples, the content of $\mathrm{SiO}_{2}$ was $53.1 \%$, which was relatively high, contributing to the highest hardness and deformation resistance of these samples. The surface of the particles was rough and irregular with a coarse texture. Many pores were visible. However, there were not many large holes or fissures [24].

\subsection{Sample Preparation}

The gangue material used in this test was from the "tunneling gangue" of the Datun Coal Electricity Group, whose lithology is sandstone. Studies have shown that continuous-gradation gangue samples have better deformation resistance than single-gradation gangue samples or discontinuous-gradation gangue samples. Therefore, in this experiment, we prepared the crushed gangue into continuous-gradation samples [25]. Firstly, using a square-hole sieve with an aperture of $10,20,30,40,50$, and $60 \mathrm{~mm}$ to screen the coal gangue, the gangue samples of the following sizes were obtained: $10-20,20-30,30-40,40-50$, and 50-60 mm, respectively. Then, the ratios of the five different-size homogeneous-gradation (continuous-gradation) gangue samples were made according to the mass. The gangue samples prepared are shown in Figure 1. 


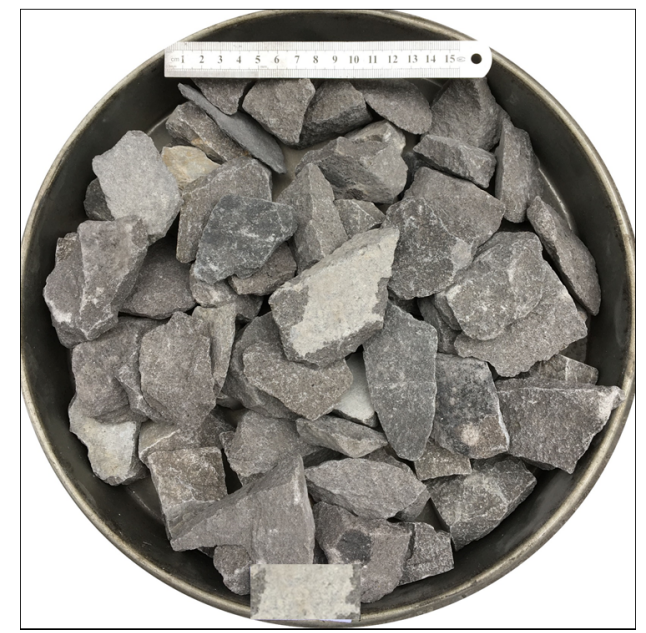

Figure 1. Gangue sample (30 40 $\mathrm{mm})$.

\subsection{Experimental Design}

$\mathrm{AE}$ is a common physical phenomenon; most materials produce $\mathrm{AE}$ signals during deformation and fracture. The monitoring and analysis of $\mathrm{AE}$ signals and the use of AE signals to infer the internal property changes of materials and structures are called AE technologies. The elastic wave emitted from the AE source finally propagates to the surface of the material, causing the surface displacement that can be detected by the AE sensors. Then, the AE signals are analyzed and inferred to understand the mechanism of AE from the material [26].

The test used two sets of equipment: a loading control system and an AE-monitoring system. The loading control system was the MTS815.02 rock mechanical electro-hydraulic servo test system. The AE-monitoring system adopted the PCI-2 AE test and an analysis system produced by Physical Acoustic Corporation of the United States (PAC). It can count and store AE parameters automatically and communicate with computers to realize real-time monitoring and positioning of $\mathrm{AE}$. The container used for storing loose-gangue samples was a circular steel cylinder with a depth of $270 \mathrm{~mm}$, an inner diameter of $250 \mathrm{~mm}$, and a loading height of $230 \mathrm{~mm}$. Six AE sensors were used in the test, evenly arranged at both ends of the steel cylinder. In order to ensure the coupling effect, butter was applied at the contact position between the two, and the air was squeezed and discharged, then a rubber belt was used to fix it tightly on the surface of the steel cylinder. The AE sensor installation and AE-monitoring system are shown in Figure 2.
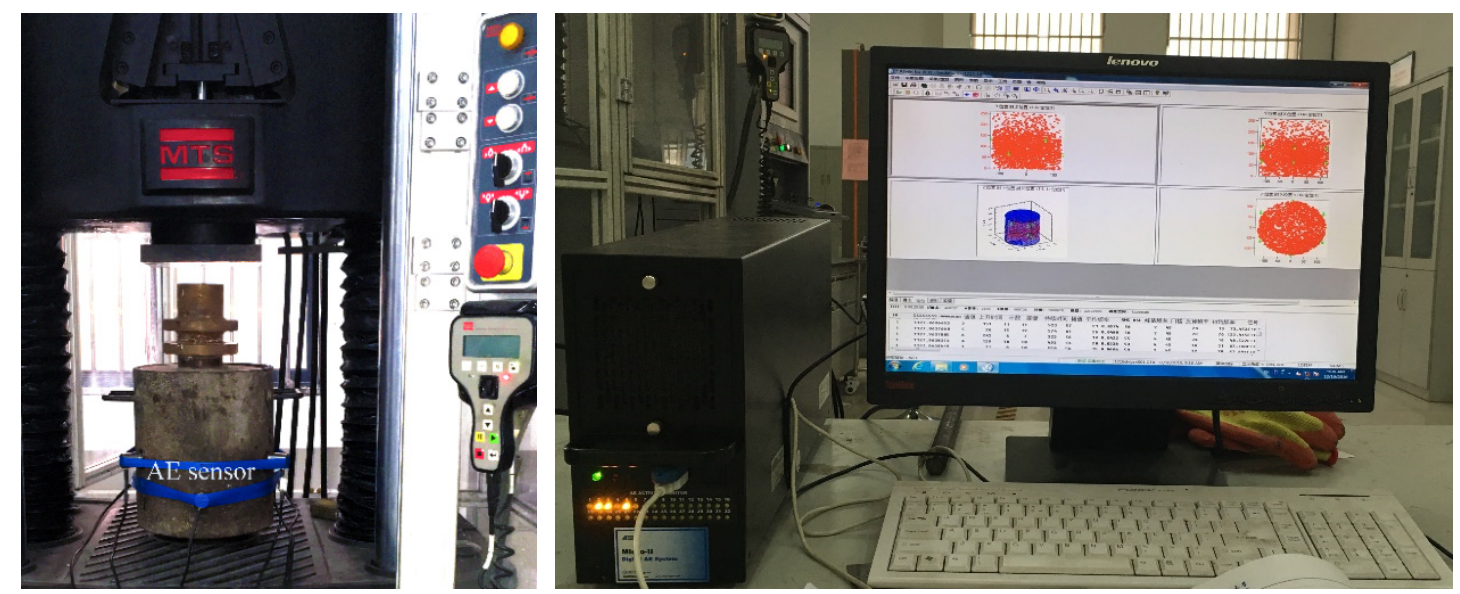

Figure 2. Acoustic emission (AE) sensor installation and AE-monitoring system. 
In this experiment, the sampling frequency of the six channels of the $\mathrm{AE}$ test and analysis system was $5 \mathrm{MSPS}(5 \mathrm{MHz}$ ), the gain of preamplifier was $40 \mathrm{~dB}$, the high-pass filter cutoff was $1 \mathrm{kHz}$, and the low-pass filter cutoff was $400 \mathrm{kHz}$. As the AE signal was greatly affected by environmental noise, a fixed threshold value was set as $45 \mathrm{~dB}$ in this test after repeated debugging, which can shield the environmental noise.

\subsection{Test Scheme}

The loading methods commonly used in the bearing compression experiments of broken gangue are the strain-control loading method and stress-control loading method. In order to ensure the stability of the loading process and the uniformity of the pressure increase, the stress loading method was adopted in this experiment. The $\mathrm{AE}$ characteristics of the confined compression process of gangue under different loading rates were studied by changing the loading rate of stress during the test. Seven test schemes were designed in this experiment, as shown in Table 1. In each scheme, when the axial stress reached $16 \mathrm{MPa}$, the loading stopped and the experiment ended. The specific test scheme is shown in Table 1. During the test, the loading process was synchronized with the AE monitoring, and the system automatically recorded load, deformation, AE events, and other parameters.

Table 1. Experimental scheme design.

\begin{tabular}{cccccccc}
\hline $\begin{array}{c}\text { Experimental scheme } \\
\text { number }\end{array}$ & $\# 1$ & $\# 2$ & $\# 3$ & $\# 4$ & $\# 5$ & $\# 6$ & $\# 7$ \\
\hline Loading rate $(\mathrm{kN} / \mathrm{s})$ & 0.5 & 1.0 & 1.5 & 2.0 & 5.0 & 10.0 & 15.0 \\
\hline
\end{tabular}

$\mathrm{AE}$ results can be used to deduce the change of internal state and mechanical properties of rocks. The commonly used AE characterization parameters mainly include counting, energy, amplitude, AE counts, energy release rate, and location. These parameters can characterize the internal changes of rocks in varying degrees. In this study, the variation rule of strain, $\mathrm{AE}$ counts, and cumulative $\mathrm{AE}$ counts with time in the process of confined compression of gangue under different loading rates were monitored, then the characteristics of AE in the process of confined compression were analyzed.

\section{Results and Discussion}

\subsection{Characteristics of Deformation Resistance}

The stress-control method was adopted in the test. The minimum loading rate was $0.5 \mathrm{kN} / \mathrm{s}$, and the maximum loading rate was $15 \mathrm{kN} / \mathrm{s}$. Seven groups of tests were designed to test the confined compression of gangue under seven different loading rates. Each group of tests was repeated three times, and the average values of the three tests were taken as the final test results. The stress-strain $(\sigma-\varepsilon)$ curves of gangue under confined compression at different loading rates are shown in Figure 3. In this study, the strain at the end of each experiment (the axial stress reached $16 \mathrm{MPa}$ ) was defined as the maximum strain of the gangue samples. The maximum strain-loading rate curve of gangue under confined compression at different loading rates is shown in Figure 4. The deformation resistance of crushed gangue was measured by the deformation of the sample when it was loaded to the same stress level. The smaller the amount of deformation, the greater the resistance to deformation was. 


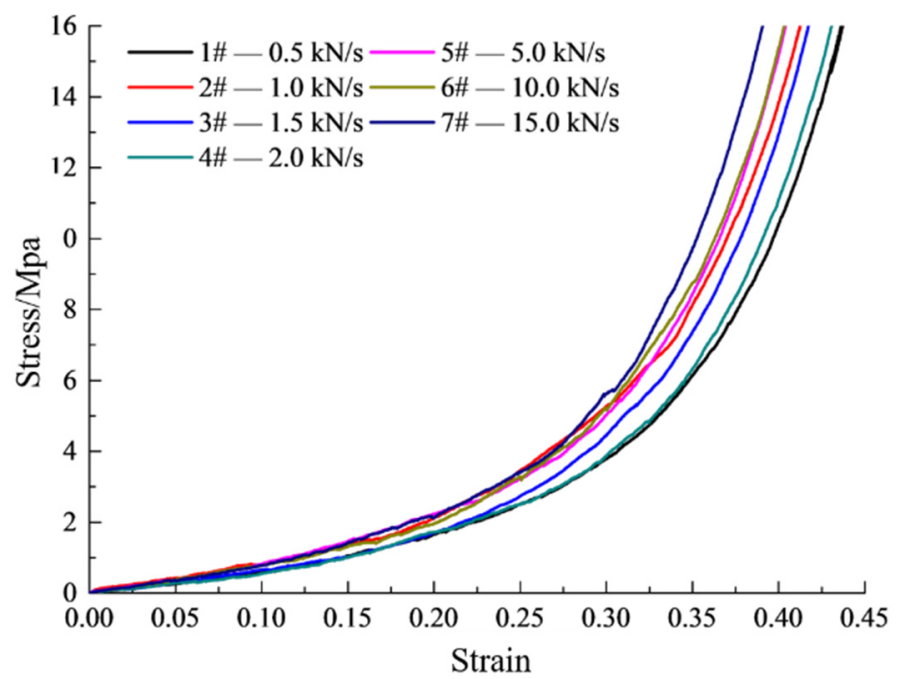

Figure 3. Stress-strain curves of the confined compression of gangue under different loading rates.

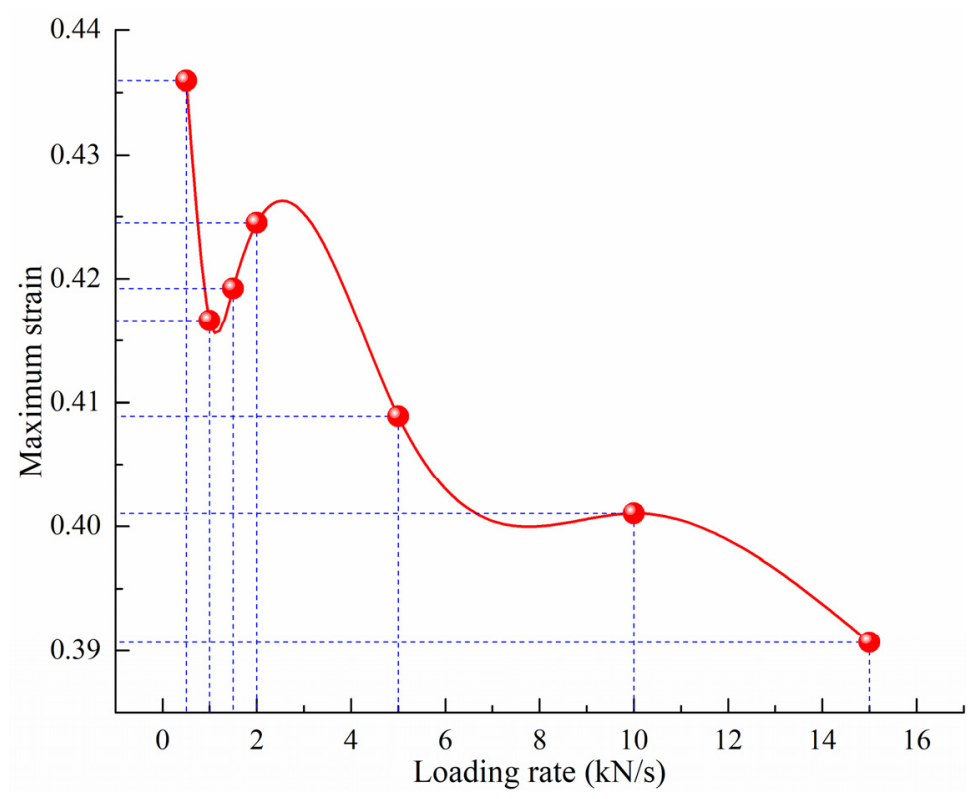

Figure 4. Maximum strain-loading rate curve of the confined compression of gangue.

As shown in Figures 3 and 4:

The trend of the stress-strain curves of crushed gangue under confined compression was the same under different loading rates, but with the increase of loading rate, the maximum strain of the sample showed a dynamic change process of decreasing, increasing, and then decreasing again. It can be seen that the loading rate had a great influence on the mechanical properties and deformation characteristics of filling gangue. This was because there were holes and cracks in the gangue block. At a low loading rate, the sample of gangue was broken sufficiently. Large-sized gangue was broken into small-sized gangue. Through the cooperation between large-sized gangue and small-sized gangue, the closure of holes and cracks was relatively high. Moreover, there was enough time for the particle rearrangement, so as to enhance the deformation resistance of the sample, and the maximum strain decreased. With the increase of loading rate, the closure of holes and cracks in the gangue was insufficient, and the position adjustment was not timely, the deformation resistance of the sample decreased, and the maximum strain increased. However, at a high loading rate, the gangue could not be fully broken, the internal holes and cracks could not be closed, and the internal position could not be adjusted, which could only lead to the breakage of some harder gangue. To a certain extent, the deformation resistance of the 
sample was improved, and the strain decreased. On the whole, the higher the loading rate, the stronger the deformation resistance of the broken gangue samples was.

\subsection{Crushing Characteristics}

Under the action of high stress, the phenomenon of grain breakage of coal gangue is usually highly significant. Grain breakage has a very important influence on the strength of coal gangue, especially deformation. Therefore, it is necessary to further study the phenomenon of grain breakage. In order to study the effect of grain breakage on the strength and deformation characteristics of crushed gangue, it is necessary to quantitatively reflect the degree of grain breakage. At present, the commonly used quantitative indicators in geotechnical engineering are the Marsal breakage ratio $\left(B_{g}\right)$ [27], control of grain size difference $(B)$ [28], and relative breakage ratio $\left(B_{\mathrm{r}}\right)$ [29]. The Marsal breakage ratio is defined as the sum of positive values of difference in gradation content before and after the test, which is given by:

$$
B_{\mathrm{g}}=\sum\left(W_{\mathrm{ki}}-W_{\mathrm{kf}}\right)
$$

where $W_{\mathrm{ki}}$ is the particle content of a certain gradation before the test, and $W_{\mathrm{kf}}$ is the corresponding gradation particle content after the test.

The Marsal breakage ratio is a multi-gradation difference summation method, which can reflect the full aspect of particle crushing. This method is simple, with clear physical characteristics, and meets the practical engineering accuracy. Therefore, in this paper, the Marsal breakage ratio $\left(B_{g}\right)$ is chosen to represent the degree of particle breakage.

The samples after the confined compression test of gangue under different loading rates were screened, and the grain size content and breakage rate before and after the test were obtained, as shown in Table 2.

Table 2. The content of particle size and crushing rate before and after gangue test at different loading rates.

\begin{tabular}{|c|c|c|c|c|c|c|c|c|}
\hline \multirow{2}{*}{\multicolumn{2}{|c|}{ Sample name }} & \multicolumn{6}{|c|}{ Percentage content of each particle size $/ \%$} & \multirow[t]{2}{*}{$\begin{array}{l}\text { Crushing } \\
\text { rate } B_{g} / \%\end{array}$} \\
\hline & & $0 \sim 10 \mathrm{~mm}$ & $10 \sim 20 \mathrm{~mm}$ & $20 \sim 30 \mathrm{~mm}$ & $30 \sim 40 \mathrm{~mm}$ & $40 \sim 50 \mathrm{~mm}$ & $50 \sim 60 \mathrm{~mm}$ & \\
\hline \multicolumn{2}{|c|}{ Before the test } & 0 & 20.00 & 20.00 & 20.00 & 20.00 & 20.00 & 0 \\
\hline \multirow{7}{*}{ 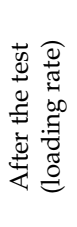 } & $0.5 \mathrm{kN} / \mathrm{s}$ & 46.84 & 19.28 & 14.56 & 9.75 & 8.84 & 0.72 & 26.84 \\
\hline & $1 \mathrm{kN} / \mathrm{s}$ & 44.34 & 20.97 & 13.00 & 9.19 & 10.56 & 1.94 & 25.31 \\
\hline & $1.5 \mathrm{kN} / \mathrm{s}$ & 44.66 & 22.66 & 16.25 & 9.91 & 3.59 & 2.94 & 27.32 \\
\hline & $2 \mathrm{kN} / \mathrm{s}$ & 42.06 & 21.44 & 16.31 & 9.84 & 10.34 & & 23.50 \\
\hline & $5 \mathrm{kN} / \mathrm{s}$ & 40.47 & 23.84 & 14.25 & 8.56 & 8.91 & 3.97 & 24.31 \\
\hline & $10 \mathrm{kN} / \mathrm{s}$ & 41.34 & 19.94 & 14.22 & 10.31 & 10.75 & 3.44 & 21.34 \\
\hline & $15 \mathrm{kN} / \mathrm{s}$ & 40.13 & 21.75 & 14.53 & 9.94 & 6.37 & 7.28 & 21.88 \\
\hline
\end{tabular}

It can be seen from Table 2:

(1) After the test, the screening results of each group of gangue samples showed that the proportion of gangue above $30 \mathrm{~mm}$ was only about $20 \%$, and the content of $0 \sim 10 \mathrm{~mm}$ gangue was above $40 \%$. Large-size gangue was obviously crushed, and the degree of crushing was large. Most of them were powdered gangue particles with a grain size of $0 \sim 10 \mathrm{~mm}$. The bearing capacity of small-size gangue samples was higher than that of large-size gangue samples, given the differences in grain size before and after the test.

(2) With the increase of loading rate, the breakage rate and stress-strain changed dynamically. At a low loading rate, the sample was broken sufficiently, and the large-sized gangue was mostly broken into small-sized gangue. With the increase of loading rate, the degree of sample breakage decreased. At a high loading rate, the gangue could not be broken sufficiently, and the proportion of large-sized gangue was higher than at a low loading rate. 


\subsection{Acoustic Emission Characteristics}

The strain, AE counts, and cumulative AE count curves of the confined compression of gangue under different loading rates are shown in Figure 5.

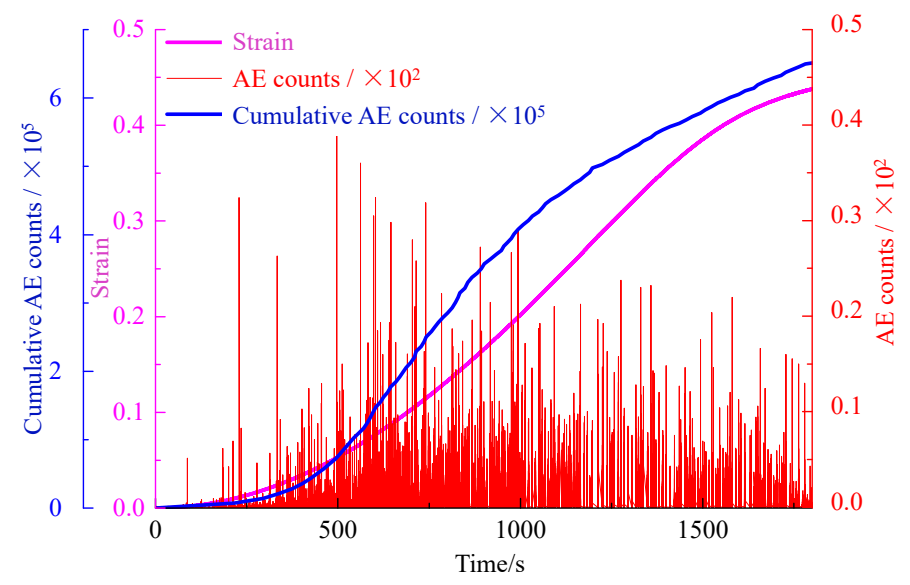

(a) Under the loading rate of $0.5 \mathrm{kN} / \mathrm{s}$.

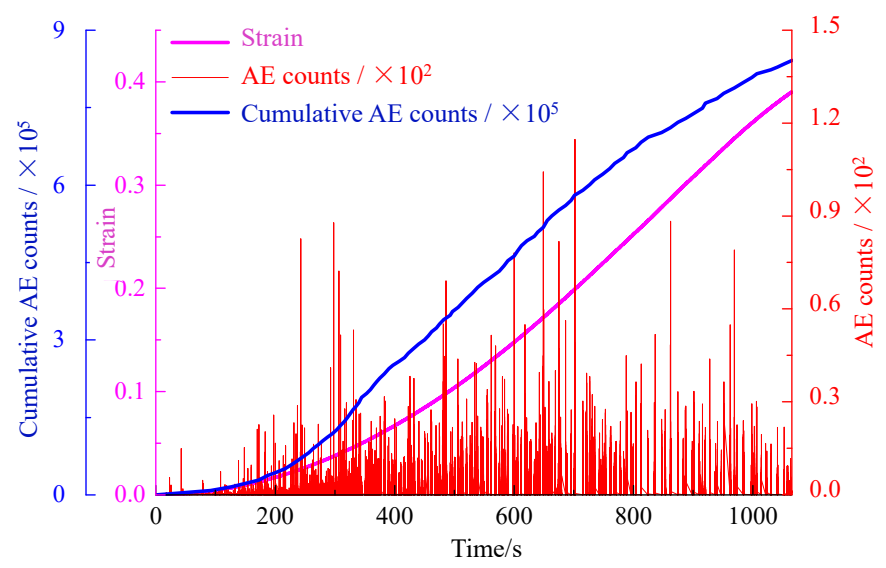

(b) Under the loading rate of $1 \mathrm{kN} / \mathrm{s}$.

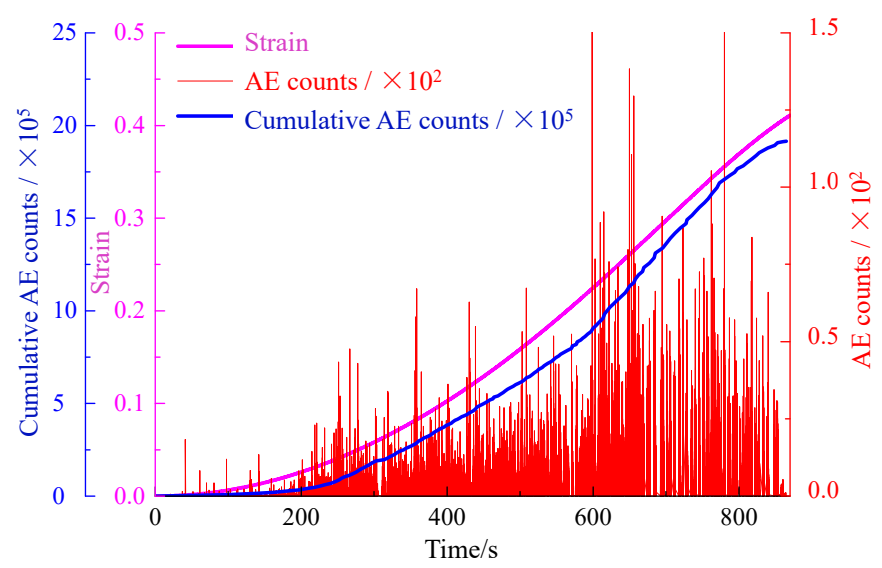

(c) Under the loading rate of $1.5 \mathrm{kN} / \mathrm{s}$.

Figure 5. Cont. 


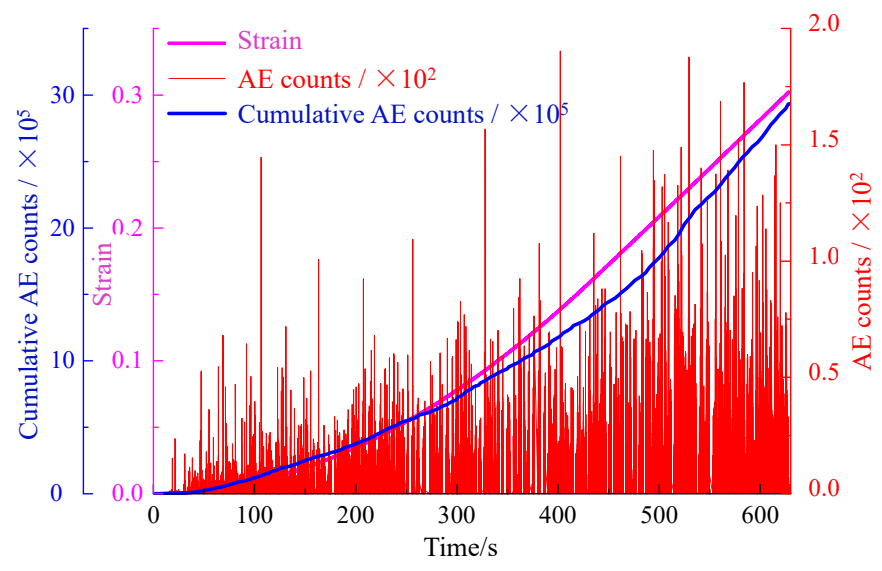

(d) Under the loading rate of $2 \mathrm{kN} / \mathrm{s}$.

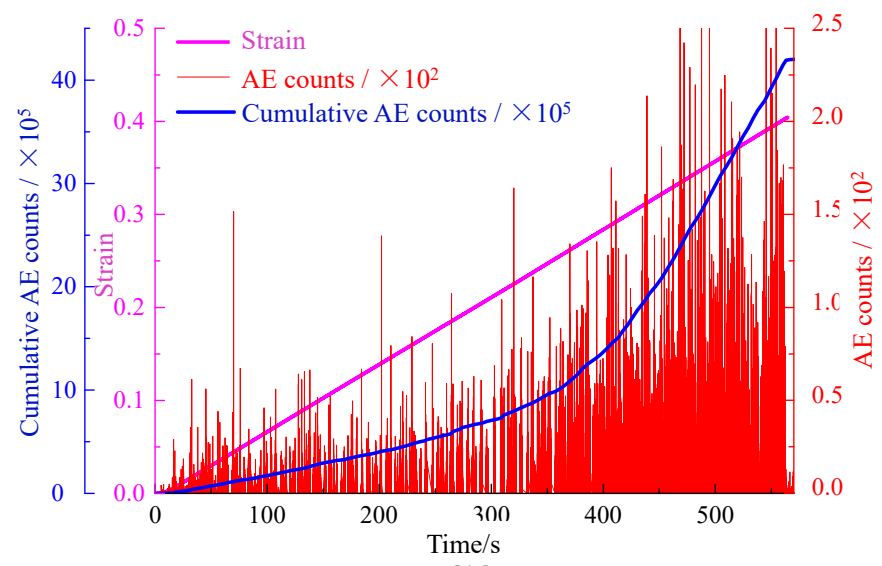

(e) Under the loading rate of $5 \mathrm{kN} / \mathrm{s}$.

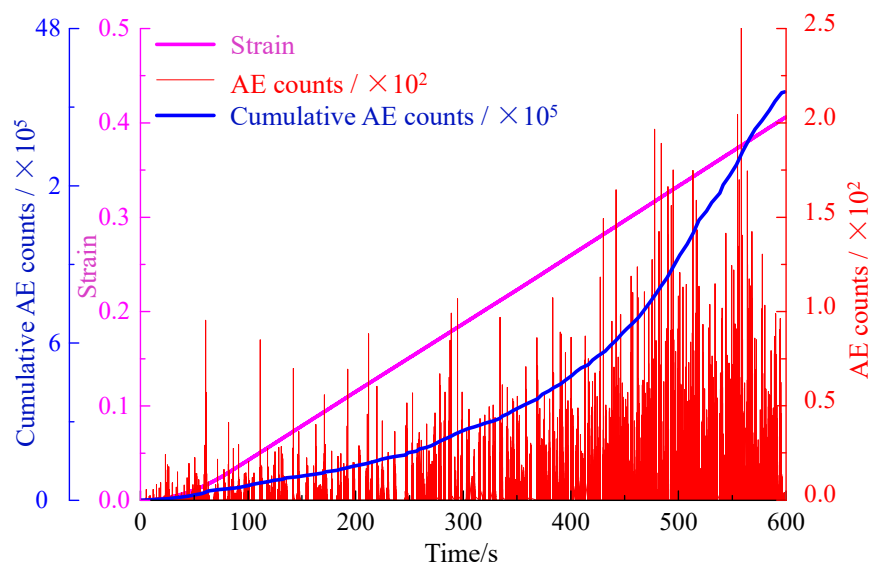

(f) Under the loading rate of $10 \mathrm{kN} / \mathrm{s}$.

Figure 5. Cont. 


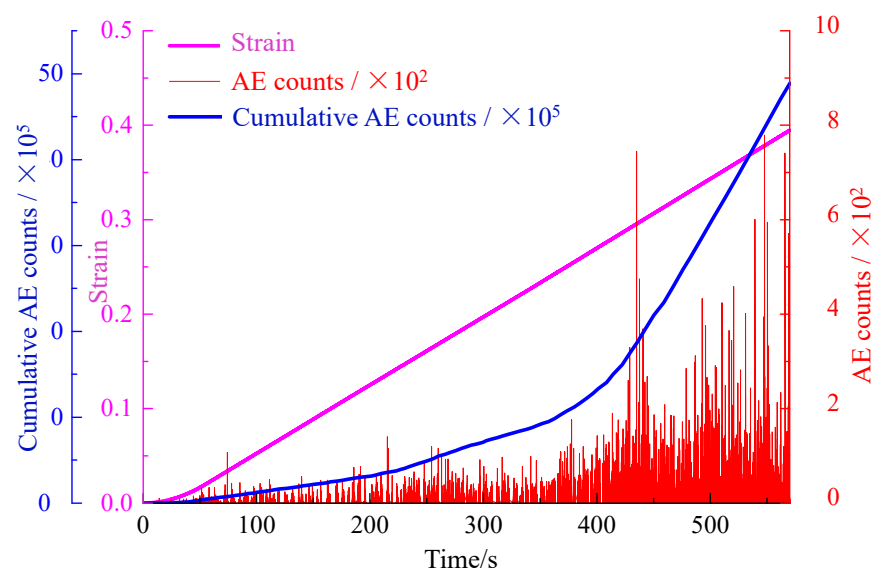

(g) Under the loading rate of $15 \mathrm{kN} / \mathrm{s}$.

Figure 5. Relationship curves between $\mathrm{AE}$ counts, cumulative $\mathrm{AE}$ counts, time, and strain of the gangue under the loading rate of (a) $0.5 \mathrm{kN} / \mathrm{s}$; (b) $1 \mathrm{kN} / \mathrm{s}$; (c) $1.5 \mathrm{kN} / \mathrm{s}$; (d) $2 \mathrm{kN} / \mathrm{s}$; (e) $5 \mathrm{kN} / \mathrm{s}$; (f) $10 \mathrm{kN} / \mathrm{s}$; (g) $15 \mathrm{kN} / \mathrm{s}$.

It can be seen from Figure 5:

(1) With the increase of loading rate, the growth period of AE counts had an obvious lag. At the same time, the AE signal changed from sparse to dense, and the cumulative counting curves gradually turned into a concave shape.

(2) The maximum AE counts of gangue samples under seven different loading rates during the entire compaction process were $0.5 \times 10^{2}, 1.14 \times 10^{2}, 1.66 \times 10^{2}, 1.90 \times 10^{2}, 2.98 \times 10^{2}, 2.94 \times$ $10^{2}$, and $7.78 \times 10^{2}$, respectively. It can be seen that with the increase of loading rate, the maximum $\mathrm{AE}$ counts were higher and the activity level of $\mathrm{AE}$ was stronger. At a higher rate, the $\mathrm{AE}$ counts increased sharply due to the gangue crushing. At the same time, the period of maximum AE counts was obviously lagging behind. In the early stage, only the friction, collision, turnover, and corner breakage between the gangue particles were the main factors, thus the AE counts were low in the early stage. Cumulative AE counts are $6.49 \times 10^{5}, 8.34 \times 10^{5}, 19.14 \times 10^{5}, 29.32 \times 10^{5}, 41.97 \times 10^{5}, 42.92 \times 10^{5}$, and $47.10 \times 10^{5}$, respectively, indicating that the AE activity level of gangue increased gradually with the increase of loading rate. At a lower loading rate, although the sample broke sufficiently, the overall breaking activity was relatively stable and not intense. With the increase of loading rate, the holes and cracks in samples could not be closed, and the internal position could not be adjusted. Under the action of overlying pressure, some harder gangue was broken, resulting in a sharp increase in AE counts, the curve showing a concave shape, and the energy of crushing increasing sharply as well.

(3) After compaction by a rammer, broken gangue materials filled into goaf become the main bodies bearing the weight of overlying rock layers, whose capacity for resisting deformation is one of the crucial factors controlling layer movement and surface subsidence. The compacting rate of rammers plays an important role in the capacity for resisting deformation by influencing the process of breaking gangue. The research results showed that as the loading rate increased, the breaking rate decreased, the gradation became more continuous, and the capacity for resisting deformation improved. This can be demonstrated by the fact that hard and bigger blocks generate stronger acoustic emission signals when they are broken than smaller ones. As a result, if geological conditions and mining equipment in mining fields are appropriate, the compacting rate of rammers should be increased as much as possible, in order to reduce the breaking rate of backfill materials, strengthen the capacity for resisting deformation, and improve backfill effect.

\subsection{A comparative Discussion with Existing Studies}

At present, relevant reports of crushed gangue's bearing compression characteristics mainly focus on the particle size distribution, stress level, and macroscopic deformation. In addition, the final 
crushing ratio of crushed gangue samples is mainly obtained by screening the samples after the experiment [30-42]. However, there is no research on particle crushing characteristics during the loading process, especially under the compression condition of different loading rates. Therefore, in this paper, a new method of monitoring the samples' AE signals during compression by an AE system is proposed to study the particle crushing state. The particle breaking characteristics of the broken gangue in the process of bearing compression were obtained, and a relationship between AE signals and particle crushing was established. Finally, the influence mechanism of the bearing compression rate on the fracture characteristics of gangue particles was revealed. The research results can provide a more in-depth and comprehensive understanding of the mechanical properties of crushed gangue filling materials.

\section{Conclusions}

In this study, $\mathrm{AE}$ monitoring was used to analyze the resistance to deformation and $\mathrm{AE}$ characteristics of loose gangue under different loading rates in the process of confined compression. The main conclusions were as follows:

(1) At a low loading rate, the sample was broken sufficiently, the relative position between the gangue particles was more coordinate, and the deformation resistance of the sample was strong. With the increase of loading rate, the holes and cracks in the gangue were not closed since there was insufficient time for adjustment, and the deformation resistance of the sample decreased. However, at a high loading rate, the gangue could not be fully broken, and the internal position could not be adjusted. Nevertheless, the breakage of some hard gangue increased the overall strength of the sample.

(2) The load-bearing capacity of small-size gangue samples was higher than that of large-size gangue samples. With the continuous increase of loading rate, the degree of sample breakage decreased, and the proportion of large-size gangue increased. This conclusion can provide theoretical and data support for the preparation of backfilling materials and the design of the ramming speed of ramming mechanisms in the process of solid-backfilling coal-mining engineering practice.

(3) With the continuous increase of loading rate, there was an obvious lag in the growth period of $\mathrm{AE}$ counts. The samples with the fastest loading rate per unit time exhibited higher AE counts, and the internal deformation rate and damage propagation rate were greater. The cumulative AE count curves gradually became concave, and the AE activity level of the gangue gradually increased. Because of the fast loading rate in the later stage, the overall deformation resistance of the gangue sample was lower than the loading stress, and the strain curve showed linear growth.

In this paper, the effects of loading rate on macroscopic compression deformation characteristics and particle crushing characteristics of crushed gangue were studied. In the future, it is necessary to continue to study the characteristics of porosity, pore structure, and permeability in the bearing compression process of crushed gangue, and reveal the influence of loading rate on the above internal structure parameters.

Author Contributions: J.L. and Y.H. conceived and designed the experiments; W.Z., Y.L. and S.O. performed the experiments; J.L., H.G. and W.L. analyzed the data; J.L. wrote the paper; Y.H., K.M. and L.W. modified the paper. All authors have read and agreed to the published version of the manuscript.

Funding: This research was funded by [Independent Research Projects of State Key Laboratory of Coal Resources and Safe Mining, CUMT] grant number [SKLCRSM18X004], [the National Key R\&D Program of China] grant number [2018YFC0604705], [the National Natural Science Foundation of China] grant number [51774269], and [the Innovation training program for college students in the Jiangsu province] grant number [201910290252X].

Conflicts of Interest: The authors declare no conflict of interest.

\section{References}

1. Miao, X.; Zhang, J.; Guo, G. Study on waste-filling method and technology in fully-mechanized coal mining. J. China Coal Soc. 2010, 1, 1-6. 
2. Huang, Y.; Zhang, J.; Zhang, Q.; Nie, S.-J.; An, B.-F. Strata movement control due to bulk factor of backfilling body in fully mechanized backfilling mining face. J. Min. Saf. Eng. 2012, 2, 162-167.

3. Liu, Z. Compaction Properties of Gangue and Its Application in Backfilling Coal Mining. Ph.D. Thesis, China University of Mining and Technology, Xuzhou, China, 2014.

4. Huang, Y.; Li, J.; Ma, D.; Gao, H.; Guo, Y.; Quyang, S. Triaxial compression behaviour of gangue solid wastes under effects of particle size and confining pressure. Sci. Total Environ. 2019, 693, 1-12. [CrossRef]

5. Zhang, Y.; Cao, S.; Zhang, N.; Zhao, C. The application of short-wall block backfill mining to preserve surface water resources in northwest China. J. Clean. Prod. 2020, 261, 1-15. [CrossRef]

6. Kong, X.; Wang, E.; Li, S.; Lin, H.; Zhang, Z.; Ju, Y. Dynamic mechanical characteristics and fracture mechanism of gas-bearing coal based on SHPB experiments. Theor. Appl. Fract. Mech. 2020, 105, 1-9. [CrossRef]

7. Jiang, N.; Wang, C.; Pan, H.; Yin, D.; Ma, J. Modeling study on the influence of the strip filling mining sequence on mining-induced failure. Energy Sci. Eng. 2020, 1-17. [CrossRef]

8. Li, H.; Zheng, C.; Lu, J.; Tian, L.; Lu, Y.; Ye, Q.; Luo, W.; Zhu, X. Drying kinetics of coal under microwave irradiation based on a coupled electromagnetic, heat transfer and multiphase porous media model. Fuel 2019, 256, 115966. [CrossRef]

9. Peng, K.; Zhou, J.; Zou, Q.; Yan, F. Deformation characteristics of sandstones during cyclic loading and unloading with varying lower limits of stress under different confining pressures. Int. J. Fatigue 2019, 127, 82-100. [CrossRef]

10. Kong, B.; Wang, E.; Li, Z.; Lu, W. Study on the Feature of Electromagnetic Radiation under Coal Oxidation and Temperature Rise Based on Multifractal Theory. Fractals 2019, 27, 1-14. [CrossRef]

11. Cao, S.; Yilmaz, E.; Song, W. Dynamic response of cement-tailings matrix composites under SHPB compression load. Constr. Build. Mater. 2018, 186, 892-903. [CrossRef]

12. Cao, S.; Yilmaz, E.; Song, W.; Yilmaz, E.; Xue, G. Loading rate effect on uniaxial compressive strength behavior and acoustic emission properties of cemented tailings backfill. Constr. Build. Mater. 2019, 213, 313-324. [CrossRef]

13. Cao, S.; Yilmaz, E.; Song, W.; Xue, G. Assessment of acoustic emission and triaxial mechanical properties of rock-cemented tailings matrix composites. Adv. Mater. Sci. Eng. 2019, 2019, 1-12. [CrossRef]

14. Xue, D.; Zhou, H.; Wang, Z.; Ren, W.; Zhang, M. Failure mechanism and mining-induced mechanical properties of coal under different loading rates. J. China Coal Soc. 2016, 41, 595-602.

15. Song, Y.; Xing, T.; Deng, L.; Zhao, Z. Experimental study of evolution characteristics of rock deformation field at different loading rates. Rock Soil Mech. 2017, 38, 2773-2779, 2788.

16. Xing, T. Experimental Study on Deformation Field Evolution and Acoustic Smission Characteristics of Rock Affected by Loading Rate. Master's Thesis, North China University of Technology, Beijing, China, 2017.

17. Li, H.; Jiang, C.; Jiang, Y.; Wang, H.; Liu, H. Mechanical behavior and mechanism analysis of coal samples based on loading rate effect. J. China Univ. Min. Technol. 2015, 44, 430-436.

18. Li, H. Evaluation Method and Application of Coal Burst Performance under the Effect of Loading Rate. Ph.D. Thesis, China University of Mining \& Technology, Beijing, China, 2014.

19. Xie, G.; Chang, J.; Hua, X. Influence of mining velocity on mechanical characteristics of surrounding rock in fully mechanized top-coal caving face. Chin. J. Geotech. Eng. 2007, 29, 963-967.

20. Cao, A.; Jing, G.; Dou, L.; Wang, G.; Liu, S.; Wang, C.; Yao, X. Damage evolution law based on acoustic emission of sandy mudstone under different uniaxial loading rate. J. Min. Saf. Eng. 2015, 32, 923-928, 935.

21. Jiang, Y.; Li, H.; Zhao, Y.; Zhou, K. Effect of loading rate on energy accumulation and dissipation in rocks. J. China Univ. Min. Technol. 2014, 43, 369-373.

22. Xiao, X.; Ding, X.; Zhao, X.; Pan, Y.; Wang, A.; Wang, L. Experimental study on acoustic emission and charge signals during coal failure process at different loading rates. Rock Soil Mech. 2017, 38, 3419-3426.

23. Xiao, X.; Jin, C.; Zhao, X.; Ding, X.; Dai, L.; Xu, J. Experimental study on the charge criterion of coal-rock bodies burst tendency. Rock Soil Mech. 2017, 38, 1620-1628.

24. Li, J.; Huang, Y.; Qiao, M.; Chen, Z.; Song, T.; Kong, G.; Gao, H.; Guo, L. Effects of Water Soaked Height on the Deformation and Crushing Characteristics of Loose Gangue Backfill Material in Solid Backfill Coal Mining. Processes 2018, 6, 1-15. [CrossRef] 
25. Huang, Y.; Li, J.; Teng, Y.; Dong, X.; Wang, X.; Kong, G.; Song, T. Numerical Simulation Study on Macroscopic Mechanical Behaviors and Micro-Motion Characteritics of Gangues under Triaxial Compression. Powder Technol. 2017, 320, 668-684. [CrossRef]

26. Li, J.; Huang, Y.; Qi, W.; Kong, G.; Song, T. Loose Gangues Backfill Body's Acoustic Emissions Rules during Compaction Test: Based on Solid Backfill Mining. Cmes-Comput. Modeling Eng. Sci. 2018, 115, 085-103.

27. Marsal, R.J. Mechanical Properties of Rockfill Embankment Dam Engineering; John Wiley and Sons Inc.: New York, NY, USA, 1973; pp. 109-200.

28. Fu, Z.; Feng, J. Concrete Face Rockfill Dam; Huazhong University of science \& Technology Press: WuHan, China, 1993; Volume 19, p. 45.

29. Hardin, C.S. Crushing of soil particles. J. Geotech. Eng. 1985, 111, 1177-1192. [CrossRef]

30. Li, M.; Zhang, J.; Zhou, N.; Huang, Y. Effect of Particle Size on the Energy Evolution of Crushed Waste Rock in Coal Mines. Rock Mech. Rock Eng. 2017, 50, 1347-1354. [CrossRef]

31. Ding, Q.; Song, S. An Experimental Study of Seepage Properties in Crushed Sandstone and Mudstone. Adv. Civ. Eng. 2019, 1-9. [CrossRef]

32. Gryczak, M.; Wong, J.W.; Thiemann, C.; Ferrari, B.J.D.; Werner, I.; Petzhold, C.L. Recycled low-density polyethylene composite to mitigate the environmental impacts generated from coal mining waste in Brazil. J. Environ. Manag. 2020, 260, 110149. [CrossRef]

33. Liu, S.Y.; Tong, L.Y.; Qiu, Y.; Miu, L.C. Crushable effects on engineering mechanical properties of colliery wastes. Chin. J. Geotech. Eng. 2005, 27, 505-510.

34. Liu, S.Y.; Qiu, Y.; Tong, L.Y.; Miu, L.C. Experimental study on strength properties of coal wastes. Chin. J. Geotech. Eng. 2006, 15, 199-205.

35. Li, M.; Zhang, J.; Wu, Z.; Liu, Y.; Li, A. An experimental study of the influence of lithology on compaction behaviour of broken waste rock in coal mine backfill. R. Soc. Open Sci. 2019, 6, 1822054. [CrossRef]

36. Sitharam, T.G.; Vinod, J.S. Evaluation of Shear Modulus and Damping Ratio of Granular Materials Using Discrete Element Approach. Geotech. Geol. Eng. 2010, 28, 591-601. [CrossRef]

37. Yan, H.; Zhang, J.X.; Zhang, S.; Mei, X.C.; Chen, J.L. Macro-micro research on compaction properties of granular backfilling materials. J. China Coal Soc. 2017, 42, 413-420.

38. Zhou, N.; Han, X.; Zhang, J.; Meng, L. Compressive deformation and energy dissipation of crushed coal gangue. Powder Technol. 2016, 297, 220-228. [CrossRef]

39. McDowell, G.R.; Khan, J.J. Creep of granular materials. Granul. Matter 2003, 5, 115-120. [CrossRef]

40. Vallejo, L.E.; Lobo-Guerrero, S.; Chik, Z. A Network of Fractal Force Chains and Their Effect in Granular Materials under Compression; Springer: London, UK, 2005; pp. 67-80.

41. Wang, W.; Li, H.M.; Xiong, Z.Q.; Su, Y.S.; Zhang, P. Research on the influence of diameter gradation on compressive deformation characteristics of gangues. Chin. J. Undergr. Space Eng. 2016, 12, 1553-1558, 1694.

42. Xin, Y.J.; Hao, H.C.; Lv, X.; Ji, H.Y. Mechanism of particle size influence on mechanical properties of broken gangue under dynamic lateral pressure. Chin. J. Undergr. Space Eng. 2018, 14, 600-606.

(C) 2020 by the authors. Licensee MDPI, Basel, Switzerland. This article is an open access article distributed under the terms and conditions of the Creative Commons Attribution (CC BY) license (http://creativecommons.org/licenses/by/4.0/). 